\title{
Supramolecular Characterization of Humic Acids Obtained through the Bacterial Transformation of a Low Rank Coal
}

\author{
Nelson O. Valero, ${ }^{*, a}$ Liliana C. Gómez ${ }^{b}$ and Luz M. Melgarejo ${ }^{c}$ \\ ${ }^{a}$ Facultad de Ciencias Básicas, Universidad de La Guajira, km 5 vía Maicao, \\ 440007 Riohacha, Colombia \\ ${ }^{b}$ Departamento de Licenciatura en Ciencias Naturales y Educación Ambiental, \\ Laboratorio de Investigación Microbiología Agrícola y Ambiental, Universidad Popular del Cesar, \\ Campus Sabana, 200003 Valledupar, Colombia \\ ${ }^{c}$ Laboratorio de Fisiología y Bioquímica Vegetal, Facultad de Ciencias, \\ Universidad Nacional de Colombia, Ciudad Universitaria, 111321 Bogotá, Colombia
}

\begin{abstract}
The humic acid (HA) obtained with the activity of three bacterial strains that transformed a lignite-type low rank coal (LRC) and released humified organic matter (HOM) was characterized. The HA obtained with the activity of Bacillus mycoides, Microbacterium sp. and Acinetobacter baumannii were compared with HA obtained with the traditional alkaline extraction method using $\mathrm{NaOH}$ 0.5 M (HA-NaOH). These characterizations included the elemental composition (C, H, N, O), Fourier transform infrared (FTIR) analysis, cross polarization-magic angle spinning-nuclear magnetic resonance $\left({ }^{13} \mathrm{C}\right.$-CPMAS-NMR), tetramethylammonium hydroxide (TMAH)-thermochemolysis followed by gas chromatography-mass spectrometry (GC-MS) and size exclusion chromatography. The two evaluated HA types showed differences in the elemental composition, aromaticity degree, content of aliphatic groups, molecular weight, polydispersity, profile of the spectra ${ }^{13} \mathrm{C}$-CPMAS-NMR and products of TMAH-thermochemolysis. The results indicate that the process of biotransformation of LRC with bacterial activity results in the structural transformations of HA, which leads to the formation of HA with a lower degree of aromaticity, more of a hydrophilic tendency, lower oxygen content, enriched with nitrogenated functional groups and polar aliphatic chains, as compared with $\mathrm{HA}-\mathrm{NaOH}$. The HA generated with the three bacterial strains exhibited a high structural similarity to each other; however, some differences were evident in the type of metabolites generated by the TMAH-thermochemolysis of the HA obtained with $B$. mycoides, as well as a higher polydispersity for the HA generated with A. baumannii.
\end{abstract}

Keywords: Acinetobacter baumannii, Bacillus mycoides, coal biotransformation, Microbacterium, lignite, humic substances

\section{Introduction}

Humic substances (HS) are extensive supramolecular arrangements, which are the result of the self-assembly of heterogeneous and relatively small humic molecules that come from the partial degradation of residues of biological materials; these supramolecular associations are stabilized by hydrogen bonds and weak hydrophobic bonds such as van der Waals forces, $\pi-\pi$, and nonclassical type $\mathrm{CH}-\pi \cdot{ }^{1,2} \mathrm{HS}$ play an important role in the physical and chemical quality of soil, ${ }^{3}$ capture and stabilization of carbon, ${ }^{4}$ inactivation of pesticides, heavy metals and other pollutants; ${ }^{5}$ and stimulate

*e-mail: nvalerov@uniguajira.edu.co plant growth and development, ${ }^{6,7}$ induce root proliferation, changing the architecture of the root system, ${ }^{8}$ and stimulate plant physiology. ${ }^{9-11}$ Because of the set of beneficial effects described for plant physiology, nutrition and growth, these substances have been called plant biostimulants. ${ }^{12-14}$ Humic substances also cause stimulation in the growth and activity of the microbial community associated with the rhizosphere, ${ }^{15}$ enhance changes in root exudation profiles and improve performance of beneficial endophytic bacteria, ${ }^{16}$ so Canellas and Olivares ${ }^{12}$ considered the use of humic acids (HA) as a component of new bioinoculants generation designs for sustainable agriculture.

On the other hand, for the role of humified organic matter in environmental topics such as mitigating greenhouse gases 
emissions, recent findings suggest it is important because anaerobic methane oxidation in sediments may contribute considerably to decreasing $\mathrm{CH}_{4}$ emission (up to $50 \%$ in these habitats), which is linked to the microbial reduction of redox functional groups present in natural organic matter since the humic fraction can serve as a terminal electron acceptor. ${ }^{17}$ In biorremediation topics, humic matter plays a notable role because of the contribution of humus-reducing microorganisms in relevant environmental processes such as biodegradation of recalcitrant pollutants in water soils and sediments, where humic substances act as terminal electron acceptors for bioremediation purposes; on the other hand, humic substances can also play an important role in the redox conversion of contaminants in engineered treatment systems. ${ }^{18}$

Because of the popularization of the use of humic amendments for agriculture and applications of humic matter-based products for environmental remediation, as well as the possibility of using several sources of humified organic matter (HOM) for the development and scaling of a new type of plant biostimulants to improve plant biomass, crop yield and resistance to multiple types of stress,,${ }^{14}$ it has become necessary to adapt analysis and characterization schemes in order to provide criteria for quality control and to try to predict the effects on plants, soil properties, soil microbiota and cross interaction with native HOM. Thus, HS components and their structural characteristics in organic amendments are parameters of maturity and stability, guaranteeing a safe and convenient impact on soil. Senesi et al. ${ }^{19}$ proposed that the most reliable and appropriate test to assess the maturity of any organic material should be based on analysis of the structural, molecular, and functional "identity" in addition to the properties of the components of the HS present in the organic amendments. This approach, called humeomics, ${ }^{20}$ allows a direct view, with a molecular basis of the intrinsic properties of organic amendments. ${ }^{21}$ Moreover, a supramolecular level analysis evaluates the possible modifications induced by the organic amendments for the state, quality, chemistry and functions of the native HS of a soil.

Low-rank coals (LRC), such as lignite and leonardita, are traditional sources for obtaining HS that are commonly extracted with alkaline solutions. ${ }^{22}$ Alternatively, HS production through microbial solubilization of LRC has been studied to generate products with higher added value, in comparison with products obtained with alkaline extraction or physical transformation, and with various applications such as obtaining liquid fuels, molecules for chemical synthesis and medicinal products. ${ }^{23}$

In a previous study, we studied the ability of native soil bacteria to biotransform a lignite-type LRC, which is generated in Colombian open cast coal mining. ${ }^{24,25} \mathrm{We}$ observed that LRC transformation occurs through the coal solubilization mechanisms described by Hofrichter and Fakoussa. ${ }^{26}$ The potential use of this material was determined as a source of HOM, in order to exploit this resource in processes of post-mining land reclamation, where the slow release of HOM is done with the microbial activity on LRC. Three outstanding bacterial strains in the production of HS from LRC were selected and identified; these isolates were denominated coal solubilizing bacteria (CSB). ${ }^{25}$

On the other hand, it has been found that the effects on soil properties and bioactivity of HS are related to the structural characteristics; ${ }^{27}$ in addition, it has been observed that the HS extracted from LRC through conventional extraction generate plant physiological responses that are lesser than those generated by HS extracted from compost or vermicompost, which have been the object of greater interaction with microorganisms that can influence the structure and properties; ${ }^{12}$ other characteristics such as hydrophobicity degree also have been related to bioactivity. ${ }^{28}$

It is necessary to define the characteristics of HS generated with bacterial transformation of LRC. According to the above, the objective of this study was to characterize the supramolecular structures of the HA fraction obtained with CSB activity on LRC (HA-CSB), as compared with HA obtained with the traditional alkaline extraction method (HA-NaOH) as a basis for future studies on the effects in the soil structure, such as plant growth and development, or indirect effect on plant growth, promoting microorganisms. This as a strategy of soil management in agriculture or in disturbed soils with a low organic carbon content, or in constructed Technosols, in post-coal mining land reclamation activities using LRC as a source of HOM that is susceptible to being released by soil microbiota, as well as applications for coal transformation for other industrial or environmental purposes.

\section{Experimental}

\section{Materials and methods}

\section{Obtaining $\mathrm{HA}-\mathrm{CSB}$ and $\mathrm{HA}-\mathrm{NaOH}$ from $\mathrm{LRC}$}

The LRC was collected from the mantle 40 Tajo Patilla pit in the El Cerrejón coal mine (La Guajira, Colombia), located at $11^{\circ} 05^{\prime} 46^{\prime \prime} \mathrm{N}$ and $72^{\circ} 40^{\prime} 46^{\prime \prime} \mathrm{W}$. The LRC was previously selected for the isolation and evaluation of CSB. ${ }^{12}$ Diagnostic features that define the LRC, total moisture, ash content, calorific value, volatile content, fixed carbon percentage, sulfur and minerals in the ash $\left(\mathrm{Fe}_{2} \mathrm{O}_{3}\right.$, 
$\mathrm{CaO}, \mathrm{MnO}_{2}, \mathrm{MgO}, \mathrm{SrO}, \mathrm{K}_{2} \mathrm{O}, \mathrm{BaO}$ ), were determined according to the ASTM (American Society for Testing Standards and Materials) ${ }^{29}$

The HA-CSB were obtained using strains of Acinetobacter baumannii, Bacillus mycoides and Microbacterium sp., three previously selected CSB with LRC solubilizing activity associated with high production of HS. ${ }^{25}$ Bacterial cultures were preserved in an AMSC5 medium; ${ }^{24}$ a colony of each strain was picked and inoculated in tubes containing $10 \mathrm{~mL}$ of nutrient broth supplemented with commercial HS (Humus Alfa 15®) at $0.001 \%$ to induce coal solubilizing activity. ${ }^{30}$ The cultures were incubated at $32{ }^{\circ} \mathrm{C}$ for $48 \mathrm{~h}$, then the entire culture volume was transferred to a flask with $250 \mathrm{~mL}$ of nutrient broth (Merck $\left.{ }^{\circledR}\right)$ and $25 \mathrm{~g}$ of LRC powder that were previously sterilized with autoclaving at $121{ }^{\circ} \mathrm{C}$ for $15 \mathrm{~min}$; these cultures were incubated at $28 \pm 2{ }^{\circ} \mathrm{C}$ with orbital shaking at $420 \mathrm{rpm}$ for 7 days. Subsequently, the cultures were centrifuged at $3200 \mathrm{rpm}$ for $15 \mathrm{~min}$, the pellet of bacterial biomass was discarded, and the supernatant was subjected to a centrifugation procedure three times; the brown dark supernatant was filtered with Whatman paper, $2.5 \mu \mathrm{m}$ pore diameter, to obtain the total humic extract (THE). The THE was treated with $0.5 \mathrm{~mol} \mathrm{~L}^{-1} \mathrm{HCl}$ to $\mathrm{pH} 2$ and was allowed to stand for $12 \mathrm{~h}$ to allow HA precipitation, then it was centrifuged at $4000 \mathrm{rpm}$ for $15 \mathrm{~min}$; the supernatant was discarded and the resulting precipitate corresponding to the HA fraction was resuspended in water and $0.5 \mathrm{~mol} \mathrm{~L}^{-1} \mathrm{NaOH}$ was slowly added to reach a neutral $\mathrm{pH}$. For the purification of the HA, the protocol established by the International Humic Substances Society (IHSS) ${ }^{31}$ was followed with three cycles of $0.5 \mathrm{~mol} \mathrm{~L}^{-1} \mathrm{NaOH}$ solution, followed by flocculation with $0.5 \mathrm{~mol} \mathrm{~L}^{-1} \mathrm{HCl}$.

To obtain $\mathrm{HA}-\mathrm{NaOH}$, the HS were extracted following the standard method suggested by the IHSS, ${ }^{31}$ using $0.5 \mathrm{~mol} \mathrm{~L}^{-1} \mathrm{NaOH}$ with a 1:10 ratio (LRC: extractant); the mixture was allowed to incubate at $60{ }^{\circ} \mathrm{C}$ for $10 \mathrm{~h}$. After obtaining THE, the HA fraction was separated as previously described. Finally, both HA-CSB and HA-NaOH samples were dried with lyophilization.

\section{Determination of elemental composition}

Samples of $1 \mathrm{mg}$ of HA-CSB, HA-NaOH and LRC were used as the substrate for the elemental composition analysis $(\mathrm{C}, \mathrm{H}, \mathrm{N}, \mathrm{O})$ using a Fisons Interscience EA 1108 analyzer. The result was corrected for the ash content in each sample, determined by burning $50 \mathrm{mg}$ of each sample at $650{ }^{\circ} \mathrm{C}$ for $4 \mathrm{~h}$; each determination was performed three times and the results were subjected to variance analysis and media comparison with the Dunnett method.
Fourier transform infrared spectroscopy (FTIR) analysis

To obtain the IR spectrum of each sample of HA-CSB and the HA-NaOH, a PE Spectrum One spectrometer equipped with a diffuse reflectance accessory was used with accumulation of up to 100 scans per sample with a resolution of $4 \mathrm{~cm}^{-1}$. Before the FTIR analysis, solid state samples were diluted by mixing them with powdered $\mathrm{KBr}$ $5 / 100(\mathrm{~m} / \mathrm{m})$ in an agate mortar.

Analysis of ${ }^{13} \mathrm{C}$-CPMAS-NMR (cross polarization-magic angle spinning-nuclear magnetic resonance)

The ${ }^{13} \mathrm{C}$ NMR spectroscopy was carried out in the solid state using a Bruker AV-300 spectrometer, equipped with a $4 \mathrm{~mm}$ thick probe; the NMR spectra were obtained applying the following parameters: rotational speed of the rotor of $13000 \mathrm{~Hz}, 1 \mathrm{~s}$ recycle time; contact time of $0.001 \mathrm{~s}$; acquisition time of $0.002 \mathrm{~s}$, and 4000 scans per sample. The HA and LRC samples were packed in $4 \mathrm{~mm}$ zirconia rotors with Kel-F caps. 1510 points were recorded in the range of $0.002 \mathrm{~s}$. To correct the dipolar dephasing, a time delay of $0.0045 \mathrm{~s}$ was determined based on standardization previously done with a pattern of ferulic acid. ${ }^{21}$

The development of the NMR spectra was carried out with Mestre-C version 4999; the Fourier transformation was applied and the base line of each spectrum was manually corrected. For the interpretation of the ${ }^{13} \mathrm{C}$-CPMAS-NMR spectrum, the chemical shift recorded between 0 and $200 \mathrm{mg} \mathrm{L}^{-1}$ was divided into the following regions of resonance: C-alkyl (0-45 $\left.\mathrm{mg} \mathrm{L}^{-1}\right)$; methoxy Cand $\mathrm{N}-\mathrm{C}\left(45-60 \mathrm{mg} \mathrm{L}^{-1}\right)$; C-O-alkyl (60-110 $\left.\mathrm{mg} \mathrm{L}^{-1}\right)$; aromatic C (110-160 $\left.\mathrm{mg} \mathrm{L}^{-1}\right)$; C-carboxyl and carbonyl $\left(160-200 \mathrm{mg} \mathrm{L}^{-1}\right)$, then the integration of the area under the curve in each of the intervals was carried out, thus the quantitative data on the relative percentage of ${ }^{13} \mathrm{C}$ in each group were obtained. Finally, with the quantitative data, the aromaticity index for each sample of HA-BSC, $\mathrm{HA}-\mathrm{NaOH}$ and LRC was determined. ${ }^{31}$

Tetramethyl ammonium hydroxide (TMAH)thermochemolysis and gas chromatography-mass spectrometry (GC-MS) analysis

$100 \mathrm{mg}$ of each type of HA-BSC, HA-NaOH and LRC were placed in quartz capsules and were wetted with $0.5 \mathrm{~mL}$ of TMAH at $25 \%$ in methanol. This mixture was dried under a soft stream of $\mathrm{N}$; then, the capsules with the sample were placed in a Pyrex tubular reactor $(50 \times 3.3 \mathrm{~cm})$ and were heated to $400{ }^{\circ} \mathrm{C}$ for $30 \mathrm{~min}$ in a Barntead Thermolyne 21100 oven.

The gaseous products derived from the thermochemolysis were collected using a He stream of $10 \mathrm{~mL} \mathrm{~min}{ }^{-1}$ and transferred to two serial containers with $150 \mathrm{~mL}$ of 
chloroform in each one, which were kept in an ice bath. After $30 \mathrm{~min}$ of pyrolysis, the contents of the two containers with the chloroform solution were combined and carried to rotoevaporation, then the residue was dissolved in $1 \mathrm{~mL}$ of chloroform and transferred to storage in a $1 \mathrm{~mL}$ glass vial; each sample was treated three times.

The GC-MS analysis was performed on a PerkinElmer Autosystem XL using an RTX-5MS WCOT capillary column with a heated transfer line $\left(250{ }^{\circ} \mathrm{C}\right)$ to a PE TurboMassGold quadrupole mass spectrometer. The chromatographic separation was achieved with the following temperature program: $60^{\circ} \mathrm{C}$ (1 min isothermal), heated at $7{ }^{\circ} \mathrm{C} \mathrm{min}^{-1}$ to $320{ }^{\circ} \mathrm{C}$ (10 min isothermal). ${ }^{21} \mathrm{He}$ was used as the carrier gas to $1.90 \mathrm{~mL} \mathrm{~min}^{-1}$, and the inlet temperature was $250{ }^{\circ} \mathrm{C}$. For the identification of each separate substance for GC, a mass spectrum was obtained in EI (electron ionization) mode $(70 \mathrm{eV})$, and scanned in the range between $45-650 \mathrm{~m} / \mathrm{z}$ with a cyclic time of $1 \mathrm{~s}$. The identification of the compounds was based on comparison of the mass spectra with the spectra published in the database library of the NIST and real standards. With the data for the presence or absence of each compound identified in each type of HA and LRC, a principal component analysis was carried out.

\section{Size exclusion chromatography}

Each sample of HA-CSB and HA-NaOH was dissolved in a $0.1 \mathrm{~mol} \mathrm{~L}^{-1} \mathrm{NaOH}$ solution and the $\mathrm{pH}$ was adjusted to 7 , then the HA solution was treated with $0.001267 \mathrm{~mol} \mathrm{~L}^{-1}$ acetic acid to a final $\mathrm{pH}$ of $3.5 ;{ }^{21}$ the $\mathrm{HA}$ solutions were subsequently filtered through glass microfiber filters with a pore diameter of $0.2 \mu \mathrm{m}$ before each analytical run with the high-performance liquid chromatography (HPLC) equipment. To run the samples, a sodium phosphate buffer $\left(\mathrm{NaH}_{2} \mathrm{PO}_{4}, 0.0625 \mathrm{~mol} \mathrm{~L}^{-1}\right)$ at $\mathrm{pH} 7$ was used as an eluent with the addition of $0.3 \mathrm{~g} \mathrm{~L}^{-1} \mathrm{NaN}_{3}$, as a bacteriostatic agent.

The HPLC analytical system consisted of a Phenomenex column, Polysep P-3000 (250 mm, $7.8 \mathrm{~mm}$ i.d.) with the temperature controlled at $25^{\circ} \mathrm{C}$, and a PerkinElmer LC200 pump connected to two detectors in series: a spectrometer fluorescence PerkinElmer LS-3B for $\lambda_{\text {ex }}=260 \mathrm{~nm}$ and $\lambda_{\mathrm{em}}=470 \mathrm{~nm}$, and a Gilson $118 \mathrm{UV}$-Vis detector at $280 \mathrm{~nm} .0 .1 \mathrm{~mL}$ of each sample solution of HA-CSB and $\mathrm{HA}-\mathrm{NaOH}$ was injected using a Rheodyne 7125 rotary injector and eluted at a constant flow of $0.6 \mathrm{~mL} \mathrm{~min}{ }^{-1}$. The chromatograms were recorded on a PE-Nelson 900 Series interface and PerkinElmer software to integrate the area under the curve of the recorded peaks. To evaluate the reproducibility of the analysis, each sample was run three times.

To calculate the average number of the different molecular weights (Mn) of the supramolecules of HA, the average molecular weight (Mw) and polydispersity (P), a standard curve was constructed with the recorded values of these three parameters using solutions from a polymer of standards of sodium polystyrene sulfonate with molecular weights of 32000, 16800, 8400, 4300 and 1100 Da. The results were subjected to variance analysis and comparison of means with the Dunnett method.

\section{Results and Discussion}

\section{LRC characteristics}

The LRC exhibited $28.44 \%$ moisture, $11.12 \%$ ash, $47.79 \%$ volatile substances, calorific value of $4781 \mathrm{kcal} \mathrm{kg}^{-1}$, $41.09 \%$ fixed carbon and $0.13 \% \mathrm{~S}$. These results confirmed the characteristics of a lignite-type LRC with high moisture content and volatile materials, and calorific power under $6390 \mathrm{kcal} \mathrm{kg}^{-1}$. The ash minerals had values of $4.24 \% \mathrm{Fe}_{2} \mathrm{O}_{3}$, $69.3 \% \mathrm{CaO}, 0.14 \% \mathrm{MnO}_{2}, 9.37 \% \mathrm{MgO}, 0.89 \% \mathrm{SrO}, 0.05 \%$ $\mathrm{K}_{2} \mathrm{O}$ and $0.08 \% \mathrm{BaO}$.

\section{FTIR and elemental composition analysis}

Table 1 shows the elemental composition $(\mathrm{C}, \mathrm{H}, \mathrm{O}$, and $\mathrm{N}$ ) of each HA-CSB, HA-NaOH and the LRC. The percentage of nitrogen was twice as high in the HA-CSB, with respect to the $\mathrm{HA}-\mathrm{NaOH}$ and LRC. The carbon percentage was also higher in the HA-CSB. The percentage of hydrogen was greater with respect to the $\mathrm{HA}-\mathrm{NaOH}$, but the difference was smaller with respect to the hydrogen content in the LRC. The percentage of oxygen was lower for the three samples of HA-CSB than the HA-NaOH and original LRC.

The results of elemental composition indicated that the alkaline extraction generated a HA that was more oxidized, maybe because of the typical formation of $\mathrm{OH}-$ fragments and carboxyl groups after the breakup of the ester and ether bonds of the LRC structure; while in the HA-CSB, there was enrichment in nitrogen and carbon content. The value of the H/C atomic ratio also showed the maturity degree of all assessed HS because it indirectly reflects the existence of aliphatic condensed $\mathrm{C}$ structures or substitutions in cyclic structures. ${ }^{32,33}$ The atomic ratio $\mathrm{C} / \mathrm{N}$ reflected the enrichment of nitrogen structures in the HA released from the LRC with the bacterial activity. The above findings suggested the occurrence of some degree of structural modification of the HA released from the LRC with CSB activity, but the modifications of the HA structure did not alter the maturity.

Figure 1 shows the IR spectra generated by each HA-CSB and HA-NaOH. FTIR spectra exhibit the 
Table 1. Elemental composition (N, C, H, O, ash) of HA-CSB and HA-NaOH obtained from lignite type LRC $(\mathrm{n}=3)$

\begin{tabular}{lccccccc}
\hline HA sample & $\mathrm{N} \pm \mathrm{SD} / \%$ & $\mathrm{C} \pm \mathrm{SD} / \%$ & $\mathrm{H} \pm \mathrm{SD} / \%$ & $\mathrm{O} \pm \mathrm{SD} / \%$ & Ash $\pm \mathrm{SD} / \%$ & $\mathrm{C} / \mathrm{N}$ & $\mathrm{C} / \mathrm{H}$ \\
\hline HA-CSB B. mycoides & $5.64 \pm 0.08^{\mathrm{d}}$ & $51.49 \pm 0.19^{\mathrm{c}}$ & $3.83 \pm 0.02^{\mathrm{a}}$ & $36.19 \pm 1.24^{\mathrm{cd}}$ & $2.84 \pm 1.29^{\mathrm{b}}$ & 10.65 & 1.12 \\
HA-CSB A. baumannii & $5.43 \pm 0.20^{\mathrm{d}}$ & $51.32 \pm 0.71^{\mathrm{c}}$ & $3.79 \pm 0.09^{\mathrm{a}}$ & $33.76 \pm 1.82^{\mathrm{d}}$ & $5.71 \pm 0.56^{\mathrm{a}}$ & 11.02 & 1.13 \\
HA-CSB Microbacterium sp. & $4.41 \pm 0.25^{\mathrm{c}}$ & $52.86 \pm 2.44^{\mathrm{c}}$ & $3.95 \pm 0.08^{\mathrm{a}}$ & $36.56 \pm 0.70^{\mathrm{c}}$ & $2,21 \pm 0.25^{\mathrm{bc}}$ & 13.99 & 1.11 \\
HA-NaOH & $2.09 \pm 0.11^{\mathrm{b}}$ & $43.31 \pm 0.69^{\mathrm{a}}$ & $2.71 \pm 0.20^{\mathrm{c}}$ & $50.39 \pm 0.26^{\mathrm{a}}$ & $1.50 \pm 0.01^{\mathrm{c}}$ & 24.16 & 1.33 \\
LRC & $1.38 \pm 0.28^{\mathrm{a}}$ & $46.04 \pm 1.74^{\mathrm{b}}$ & $3.26 \pm 0.03^{\mathrm{b}}$ & $42.95 \pm 0.67^{\mathrm{b}}$ & $6.37 \pm 0.35^{\mathrm{a}}$ & 39.05 & 1.18 \\
\hline
\end{tabular}

HA: humic acid; CSB: coal solubilizing bacteria; LRC: low rank coal; SD: standard deviation. Treatments with different letters show significant difference (Dunnett, $\alpha=0.05$ ).

characteristic profile of HA, the presence of a wide band around of $3400 \mathrm{~cm}^{-1}$ is recorder, corresponding to $\mathrm{OH}$ groups in alcohols, free phenols and carboxylic groups; there are narrowing band around $2920 \mathrm{~cm}^{-1}$ and a band bending around $1380 \mathrm{~cm}^{-1}$, that are characteristics of $\mathrm{CH}$ link in aliphatic groups; other narrowing band near $1715 \mathrm{~cm}^{-1}$ corresponds to the $\mathrm{C}=\mathrm{O}$ group; narrowing band at $1717 \mathrm{~cm}^{-1}$ corresponds to aromatic rings; and the bending band around $1280 \mathrm{~cm}^{-1}$ corresponds to $\mathrm{C}-\mathrm{OH}$ link.
In the FTIR analysis, some differences between the spectra are observed; the $\mathrm{OH}$ band in alcohols and phenols is much more pronounced in HA obtained from Microbacterium sp. A band at $2600 \mathrm{~cm}^{-1}$ was seen in the HA samples of A. baumannii and B. mycoides, corresponding to $\mathrm{OH}$ fragment in carboxylic groups of nitrogenous compounds, and small bands around 1659 and $1540 \mathrm{~cm}^{-1}$ were associated with peptide bonds in the types I and II amides $^{34}$ present in the HA-CSB (Figure 1).

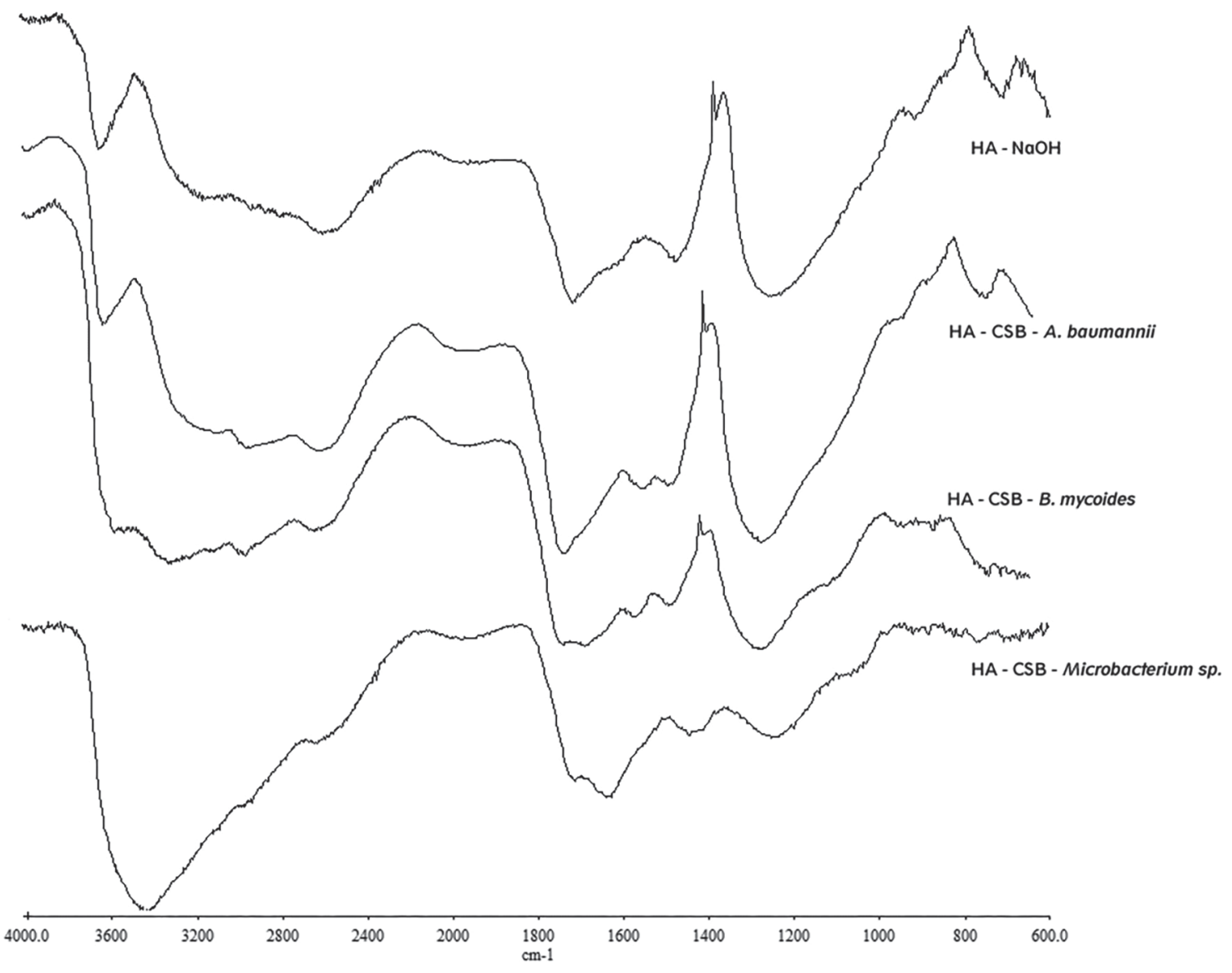

Figure 1. IR (KBr) spectra of $\mathrm{HA}-\mathrm{CSB}$ and $\mathrm{HA}-\mathrm{NaOH}$. 
Generally, the qualitative differences observed in the FTIR analysis were not relevant with regard to the predominant organic group in the macrostructure of the two types of HA. However, evidence of protein derivatives in the HA-CSB, in line with the results of the elemental composition, indicated that the bacterial activity on the LRC generated HA-enriched $\mathrm{N}, \mathrm{C}$ and $\mathrm{H}$, but with a lower oxygen content; this result showed CSB activity in the oxygen functional groups, which are the most reactive groups within the HS. Perhaps this fact is a direct consequence of the microbial metabolism that causes structural changes in HS. It has also been demonstrated the incorporation of $\mathrm{N}$ into the molecules of amino sugars and amino acids present in HA obtained with biodegradation of LRC. . $^{34,35}$

\section{${ }^{13} \mathrm{C}$-CPMAS-NMR analysis}

\section{LRC, $\mathrm{HA}-\mathrm{CSB}$ and $\mathrm{HA}-\mathrm{NaOH}$}

As can be seen in Figure 2, the three HA-CSB had very similar spectra and some differences; together with the HA-NaOH, they had marked differences from the LRC from which they are obtained. The $\mathrm{HA}-\mathrm{NaOH}$ presented a spectrum that was related to the LRC.

The spectra of the HA-CSB had larger peaks in the region corresponding to the carboxylic groups, with a predominant content of aromatic groups, smaller peaks between 110 and $60 \mathrm{mg} \mathrm{L}^{-1}$ (corresponding to the region of polysaccharides, alcohols and aminosugars), a peak at about $60 \mathrm{mg} \mathrm{L}^{-1}$ corresponding to amino acids, a small peak corresponding to methoxy groups, and, in the region of the aliphatic groups, larger peaks than the $\mathrm{HA}-\mathrm{NaOH}$.

Table 2 shows the results of the quantitative analysis of ${ }^{13} \mathrm{C}$-CPMAS-NMR, where the $\mathrm{HA}-\mathrm{NaOH}$ had a greater content of phenolic groups than the LRC; however, in the HA-CSB, the content was less. The three HA-CSB had a decreased aromatic carbon content and an increased carbon content in the alkyl groups, corresponding to nitrogen compounds; they also had an increased carbohydrate content and di-oxy alkyl groups and aliphatic compounds, in comparison to the HA- $\mathrm{NaOH}$. The determination of the aromaticity index showed that the three samples of HA-CSB had lower values with respect to the samples of LRC and $\mathrm{HA}-\mathrm{NaOH}$, which have similar values.

The results of the ${ }^{13} \mathrm{C}$-CPMAS-NMR analysis revealed a more aliphatic character of the HA-CSB associated with a decrease in the degree of condensation of aromatic structures, as seen in the decrease of the aromaticity index values (Table 2). These differences suggest that CSB can act metabolically on the original structure of the HA contained in the LRC and partially modify the structure, mainly by acting on the polyaromatic nucleus. Previously, Dong and Yuan ${ }^{35}$ found that the HA obtained with alkaline extraction from LRC contained greater amounts of aromatic structures in comparison with HA obtained with Penicillium sp. activity on the same LRC; in this study,

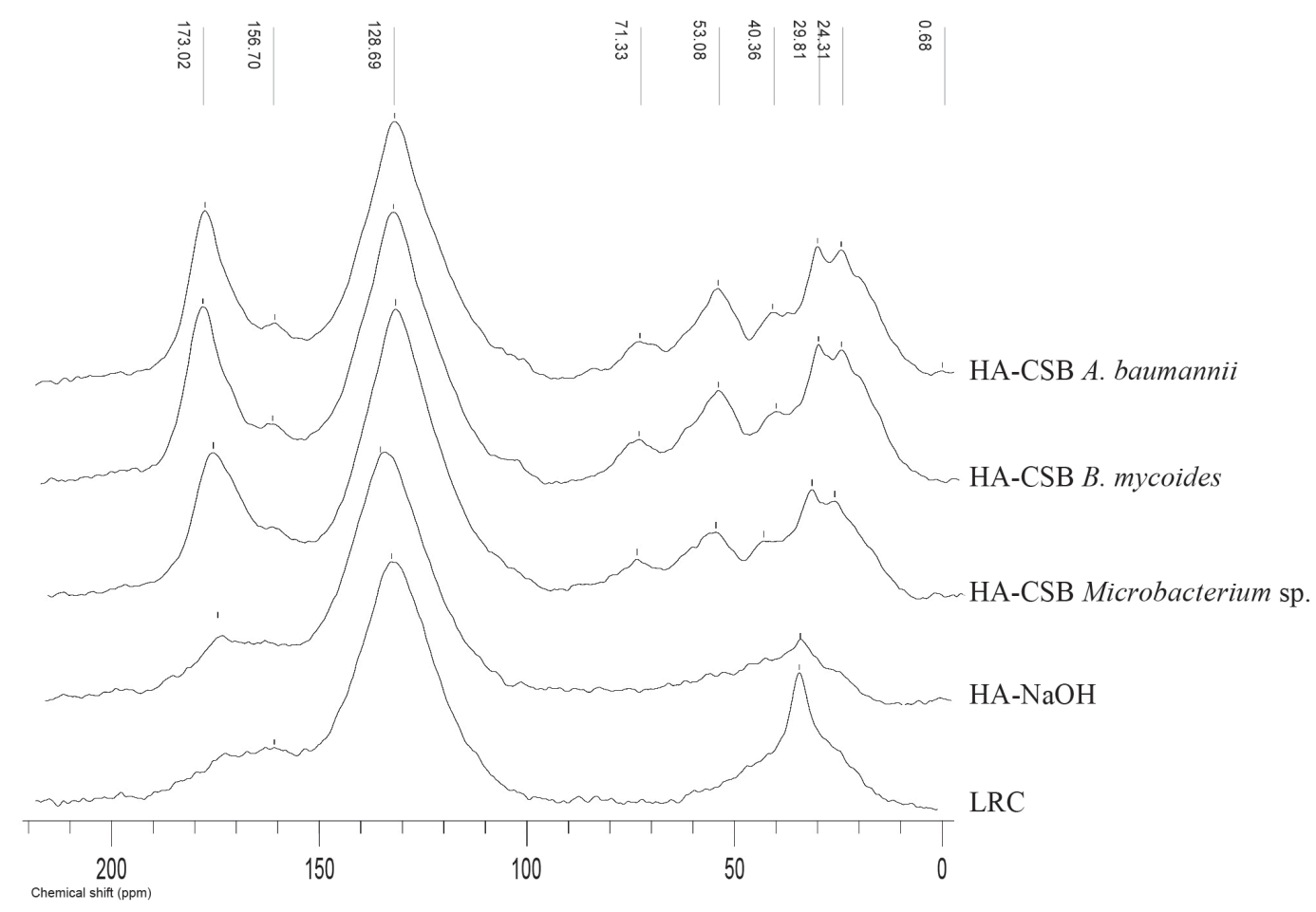

Figure 2. ${ }^{13} \mathrm{C}-\mathrm{CPMAS}-\mathrm{NMR}$ spectra of the LRC and three HA-CSB in comparison with the HA-NaOH. 
Table 2. Relative distribution of area under the curve of the chemical shift in the ${ }^{13} \mathrm{C}-\mathrm{CPMAS}-\mathrm{NMR}$ spectra of the LRC and three HA-CSB in comparison to the $\mathrm{HA}-\mathrm{NaOH}$

\begin{tabular}{|c|c|c|c|c|c|c|c|}
\hline \multirow[b]{2}{*}{ HA sample } & \multicolumn{7}{|c|}{ Relative distribution of ${ }^{13} \mathrm{C} / \%$} \\
\hline & Carboxylic & Phenolic & Aromatic & $\begin{array}{l}\text { Carbohydrates } \\
\text { and di- } O \text { alkyl }\end{array}$ & $\begin{array}{l}N \text {-Alkyl } \\
\text { methoxy }\end{array}$ & Aliphatic & $\begin{array}{c}\text { Aromaticity } \\
\text { index }\end{array}$ \\
\hline HA-CSB A. baumannii & 17.37 & 5.72 & 35.51 & 11.10 & 7.55 & 22.74 & 0.41 \\
\hline HA-CSB B. mycoides & 17.98 & 5.80 & 36.23 & 10.20 & 7.58 & 22.22 & 0.42 \\
\hline HA-CSB Microbacterium sp. & 17.37 & 6.86 & 41.67 & 10.71 & 5.90 & 17.49 & 0.49 \\
\hline $\mathrm{HA}-\mathrm{NaOH}$ & 18.27 & 10.64 & 48.71 & 6.75 & 3.93 & 11.69 & 0.59 \\
\hline LRC & 11.83 & 8.14 & 48.06 & 8.55 & 3.05 & 20.37 & 0.56 \\
\hline
\end{tabular}

HA: humic acid; CSB: coal solubilizing bacteria; LRC: low rank coal.

evidence of the same feature for HA-CSB was found; this result is consistent with the model of action that has been proposed to explain coal solubilization by bacteria. ${ }^{26}$ Also, this result confirmed the previously described ability of CSB to use a certain percentage of LRC as a carbon source for metabolism and the depolymerization phenomena of HS. ${ }^{25,36,37}$

The lower aromaticity index for HA-CSB compared with $\mathrm{HA}-\mathrm{NaOH}$, together with other described features, provides a more hydrophilic character for the HA-CSB; this feature could determine certain implications in interactions with other soil components; for example, less recalcitrance against biological activity, according to Kleber, ${ }^{38}$ a fact that may involve stimulation of microbial activity. Moreover, there may also be a greater potential for the establishment of interactions with plant roots and rhizosphere microbiota, which enhance the bioactivity phenomena that have been described for $\mathrm{HA}^{6,39,40}$ and the phenomenon of "microbial loop", ${ }^{15}$ that is the stimulation of the activity of beneficial microorganisms of the rhizosphere is explained by the consequence of an increasing release of rhizospheric exudates, as a result of stimulation of the plant metabolism induced by HS. However, a more hydrophilic characteristic of the HA, given by decreasing the aromatic condensation, can reduce the effect on the conformation of soil aggregates, which are determinant for the presence of HS with a more hydrophobic characteristic, as has been previously described. ${ }^{3,41}$

Nardi et al. ${ }^{39}$ described the bioactivity of HA (like auxin effect) as having a higher content of nitrogen groups in the structure and the hydrophilic domains. Dobbss et al. ${ }^{8}$ described the effects of processed humic materials on plant physiology, demonstrating bioactivity on root development, with HA fractions that showed a more hydrophilic characteristic and the presence of nitrogenated groups; accordingly, the content of nitrogenated groups and the more hydrophilic nature of the HA-CSB could theoretically promote the phytostimulant activity of these HA on plant roots.

\section{TMAH-thermochemolysis-GC-MS}

The total of volatile ions recorded in the chromatograms generated with the GC-MS of the LRC, the HA-NaOH and the HA-CSB (taking HA-CSB B. mycoides as an example) are shown in the pyrograms in Figure 3. The pyrogram of $\mathrm{HA}-\mathrm{NaOH}$ retained a similar pattern to that of the original LRC, with changes in the composition and magnitude peaks of compounds of lower molecular weight, which were present at the start of the chromatogram, and the aliphatic linear compounds that were high in molecular weight, which were recorded at the end of the chromatogram with a greater variety, but lesser minor amounts. The pyrogram of HA-CSB (B. mycoides) presented a different chromatographic pattern than the $\mathrm{HA}-\mathrm{NaOH}$ and the LRC; the HA-CSB had numerous peaks at the begining of the chromatogram, corresponding to different molecules with a lower molecular weight, reported as peptide derivatives; two relevant peaks, around 29 and 33 min of the column retention, were seen, which corresponded to long chain fatty acids. The HA pyrogram of the CSB did not show other long-chain alkane groups, which were recorded at the end of the chromatograms of the LRC and the HA-NaOH. This chromatographic pattern was recorded similarly to the HA-CSB obtained with the A. baumannii and Microbacterium sp. activity.

The thermochemolysis of the studied HA released 77 different molecules, identified by characterizing their mass spectra; most of them were identified as methyl esters and esters of natural compounds. The most abundant compounds were lipid hydrophobic molecules in large aliphatic and alicyclic (Lp) type plant-derived compounds $(\mathrm{Bp})$ and units derived from lignin residues $(\mathrm{Lg})$, a group of products represented by protein-derived molecules and 

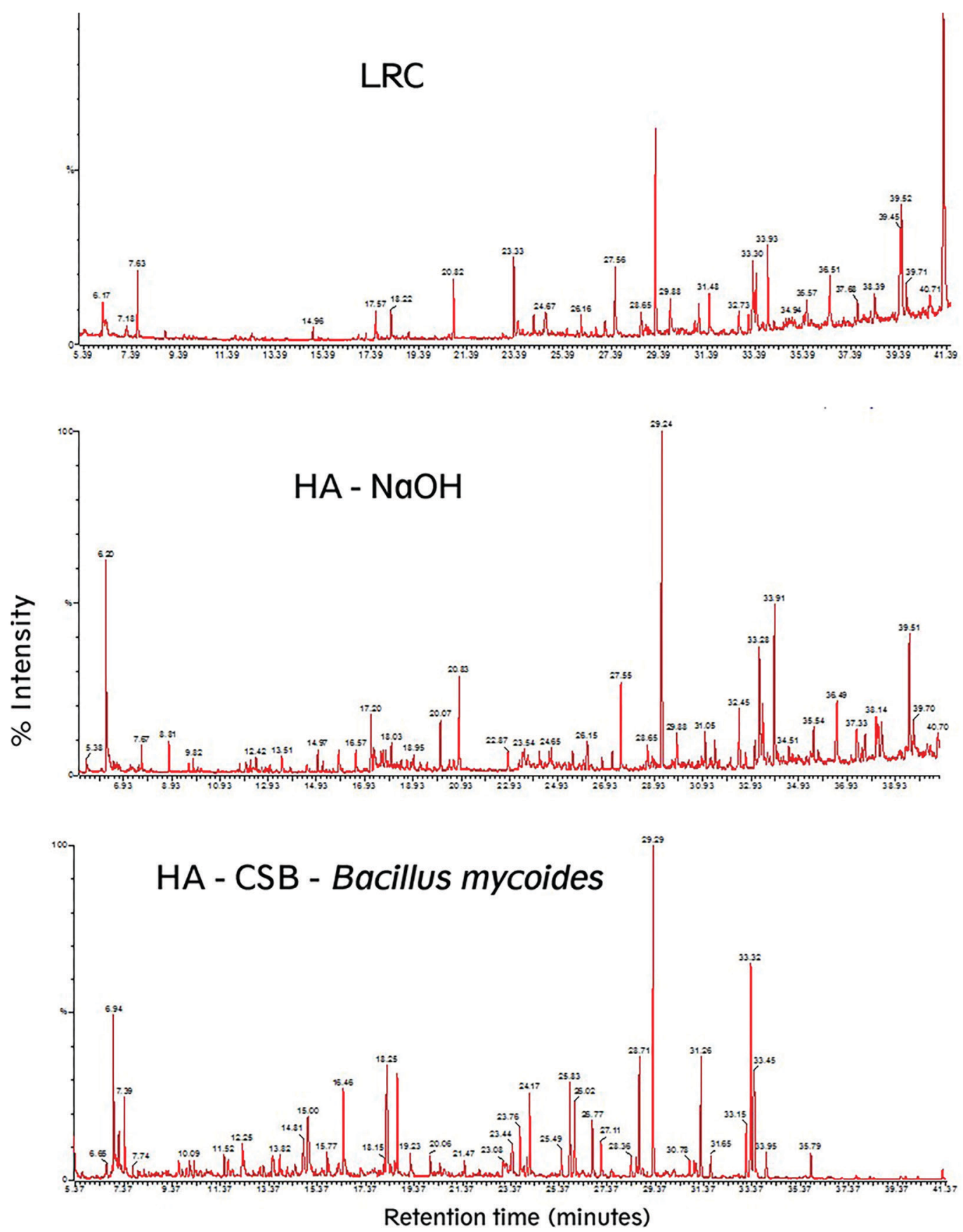

Figure 3. Chromatograms of the byproducts obtained after TMAH-thermochemolysis-GC-MS of the HA-NaOH and HA-CSB (B. mycoydes), in comparison to the LRC.

other nitrogenated compounds $(\mathrm{Pr})$ and a group represented by polymeric byproducts with a microbial origin (Mic) (Table 3).

The principal components analysis (Figure 4) showed that two components explained $69 \%$ of the variation between the samples, caused by the presence or absence of products of the thermochemolysis in each of the treated samples. The analysis revealed a greater association between the HA-CSB of the A. baumanni and Microbacterium sp. and separated the LRC from all of the HA-CSB samples; the analysis also confirmed the difference between the HA-CSB and the HA-NaOH and closer ties between the $\mathrm{HA}-\mathrm{NaOH}$ and LRC.

The TMAH-thermochemolysis-GC-MS analysis revealed that the major difference between the two types of HA was the fact that peptide derivatives are only pyrolysis products of the HA-CSB. Compounds derived from lignin include HA-CSB and $\mathrm{HA}-\mathrm{NaOH}$, for example, the methyl ester of benzoic acid and certain alkanes such as pentadecane, methyl hexadecane, methyl 
Table 3. Byproducts of tetramethylammonium hydroxide (TMAH)-thermochemolysis released from the LRC, HA-CSB and HA-NaOH

\begin{tabular}{|c|c|c|c|c|c|c|c|}
\hline $\mathrm{t}_{\mathrm{R}} / \min$ & Compound & Type & $\begin{array}{c}\text { HA-CSB } \\
\text { A. baumannii }\end{array}$ & $\begin{array}{l}\text { HA-CSB } \\
\text { B. mycoides }\end{array}$ & $\begin{array}{c}\text { HA-CSB } \\
\text { Microbacterium } \\
\text { sp. } \\
\end{array}$ & $\mathrm{HA}-\mathrm{NaOH}$ & LRC \\
\hline 7.08 & L-valine, m.e. & $\operatorname{Pr}$ & + & - & + & - & - \\
\hline 7.16 & 3-methyl-bencenamine & $\operatorname{Pr}$ & - & + & - & - & + \\
\hline 7.33 & methoxi-benzene & $\mathrm{Lg}$ & + & - & + & - & - \\
\hline 8.44 & $5 H$-1-pyridina & $\operatorname{Pr}$ & + & - & - & - & - \\
\hline 8.81 & 2-methyl-undecene & Lp & - & - & - & + & - \\
\hline 8.82 & 1-methoxi-4methyl-benzene & $\mathrm{Lg}$ & + & - & - & - & - \\
\hline 8.94 & 4-methyl- pyridine & $\operatorname{Pr}$ & + & - & - & - & - \\
\hline 9.61 & dodecene & $\mathrm{Lp}$ & - & - & - & + & - \\
\hline 9.92 & 2,4(1H,3H)-pyrimidinedioine, dihidro-3-methyl & $\operatorname{Pr}$ & + & - & - & - & - \\
\hline 10.25 & 1,3-dimethyl-2,4,5-trioxoimidazolidine & $\operatorname{Pr}$ & + & - & + & - & - \\
\hline 10.83 & 3-heptenyl-benzene & $\mathrm{Lg}$ & + & - & - & - & - \\
\hline 10.9 & isoquinoline & $\operatorname{Pr}$ & + & - & - & - & - \\
\hline 11.3 & 2 methyl- $1 H$-indole & $\operatorname{Pr}$ & + & + & - & - & - \\
\hline 12 & methyl-dodecene & Lp & - & - & - & + & - \\
\hline 12.2 & tridecene & $\mathrm{Lp}$ & - & - & - & + & - \\
\hline 12.28 & $5 H$-1-pyridine & $\operatorname{Pr}$ & - & + & - & - & - \\
\hline 12.34 & dimethyl-indole & $\operatorname{Pr}$ & + & - & - & - & - \\
\hline 13.45 & 2-methyl-5-oxo-proline, m.e. & $\operatorname{Pr}$ & + & - & + & - & - \\
\hline 13.48 & 1-methyl-5-oxo-L-proline, m.e. & $\operatorname{Pr}$ & - & + & + & - & - \\
\hline 13.51 & 4-methoxy-benzoic acid, m.e. & $\mathrm{Lg}$ & - & - & + & + & - \\
\hline 14.17 & 1,2-dimethyl-1H-indole & $\operatorname{Pr}$ & + & - & - & - & - \\
\hline 14.63 & biphenyl & $\mathrm{Lg}$ & - & - & - & + & - \\
\hline 14.84 & 5-oxo-L-proline, m.e. & $\operatorname{Pr}$ & + & - & - & - & - \\
\hline 14.97 & tetradecene & $\mathrm{Lp}$ & - & - & - & + & - \\
\hline 14.99 & glycine derivative & $\operatorname{Pr}$ & - & + & - & - & - \\
\hline 15 & tetradecane & $\mathrm{Lp}$ & - & - & + & - & + \\
\hline 15.01 & $N$-(2-methyl-1-oxo-2-butenil)-glycine, m.e. & $\operatorname{Pr}$ & + & - & - & - & - \\
\hline 15.79 & 1,3(2H)-dione, 2 -methyl- $1 H$-isoindole & $\operatorname{Pr}$ & + & + & + & - & - \\
\hline 16.53 & tyrosine derivative & $\operatorname{Pr}$ & + & - & + & - & - \\
\hline 17.2 & methyl-pentadecane & $\mathrm{Lp}$ & - & - & - & + & - \\
\hline 17.67 & pentadecane & $\mathrm{Lp}$ & - & - & + & + & + \\
\hline 18.62 & dodecenoic acid, m.e. & Lp & + & - & - & - & - \\
\hline 18.72 & dodecanoic acid, m.e. & Mic & + & + & + & - & - \\
\hline 18.96 & tetramethyl hexadecane & $\mathrm{Lp}$ & - & - & - & + & - \\
\hline 19.26 & $1 H$-indole-2,3-dione, 1-methyl-, 3-hydrazone & $\operatorname{Pr}$ & + & + & + & - & - \\
\hline 19.52 & branched alkane & $\mathrm{Lp}$ & - & - & - & + & - \\
\hline 20.07 & methyl-hexadecane & Lp & - & - & + & + & - \\
\hline 20.84 & hexadecane & $\mathrm{Lp}$ & - & - & - & + & + \\
\hline 22.9 & $9 H$-purin-6-amino- $N$-9-dimethyl & $\operatorname{Pr}$ & + & - & + & - & - \\
\hline 23.36 & heptadecane & $\mathrm{Lp}$ & - & - & - & + & + \\
\hline 23.72 & $3 H$-purin-6-amine, $N, N, 3$-trimethyl & $\operatorname{Pr}$ & + & + & + & - & - \\
\hline 24.05 & tetradecenoic acid, m.e & $\mathrm{Lp}$ & + & + & - & - & - \\
\hline 24.17 & tetradecanoic acid, m.e. & Lp & - & + & - & - & - \\
\hline 24.19 & tetradecanoic acid, m.e. & $\mathrm{Lp}$ & + & + & + & - & - \\
\hline 24.25 & branched alkane & $\mathrm{Bp}$ & - & - & - & + & - \\
\hline 24.67 & tetramethyl octadecane & $\mathrm{Bp}$ & - & - & - & + & - \\
\hline 24.91 & branched alkane & $\mathrm{Bp}$ & - & - & - & + & - \\
\hline 25.5 & branched alkane & Bp & - & - & + & - & - \\
\hline 25.82 & 13 methyl-tetradecanoic acid, m.e. & Mic & + & + & - & - & - \\
\hline 26.05 & 12 ethyl-tetradecanoic acid, m.e. & Mic & + & + & + & - & - \\
\hline 26.76 & pentadecanoic acid, m.e. & Mic & + & + & - & - & - \\
\hline
\end{tabular}


Table 3. Byproducts of tetramethylammonium hydroxide (TMAH)-thermochemolysis released from the LRC, HA-CSB and HA-NaOH (cont.)

\begin{tabular}{|c|c|c|c|c|c|c|c|}
\hline $\mathrm{t}_{\mathrm{R}} / \min$ & Compound & Type & $\begin{array}{c}\text { HA-CSB } \\
\text { A. baumannii }\end{array}$ & $\begin{array}{l}\text { HA-CSB } \\
\text { B. mycoides }\end{array}$ & $\begin{array}{c}\text { HA-CSB } \\
\text { Microbacterium } \\
\text { sp. } \\
\end{array}$ & $\mathrm{HA}-\mathrm{NaOH}$ & LRC \\
\hline 27.08 & caffeine derivative & $\operatorname{Pr}$ & - & + & - & - & - \\
\hline 27.11 & caffeine derivative & $\operatorname{Pr}$ & + & - & + & - & - \\
\hline 27.58 & octadecane & $\mathrm{Lp}$ & - & - & - & + & + \\
\hline 28.36 & methyl-pentadecanoic acid, m.e. & Mic & + & - & + & - & - \\
\hline 28.6 & hexadecenoic acid, m.e. & Mic & + & + & + & - & - \\
\hline 28.87 & nonadecane & Lp & - & - & - & + & - \\
\hline 29.27 & hexadecanoi acid, m.e. & Lp & + & + & + & + & + \\
\hline 29.91 & tetramethyl hexadecane & Lp & - & - & - & + & + \\
\hline 30.76 & 15 methyl-hexadecanoic acid, m.e. & Mic & + & + & - & - & - \\
\hline 30.95 & heptadecenoic acid, m.e. & Mic & + & + & + & - & - \\
\hline 31.06 & heptadecenoic acid, m.e. & Mic & + & - & - & - & - \\
\hline 31.06 & eicosane & $\mathrm{Lp}$ & - & - & - & - & + \\
\hline 31.24 & 14 methyl-hexadecanoic acid, m.e. & Mic & + & - & + & - & + \\
\hline 31.64 & heptadecanoic acid, m.e. & Lp & + & + & - & - & - \\
\hline 33.31 & octadecenoic acid, m.e. & Lp & + & + & + & + & + \\
\hline 33.77 & heneicosane & Lp & - & - & - & + & - \\
\hline 33.94 & octadecanoic acid, m.e. & Lp & + & + & + & - & + \\
\hline 34.72 & tetramethyl octadecane & $\mathrm{Bp}$ & - & - & - & + & - \\
\hline 35.52 & docosane & $\mathrm{Bp}$ & - & - & + & + & + \\
\hline 37.68 & dodecane & $\mathrm{Bp}$ & - & - & - & - & + \\
\hline 38.39 & tetramethyl eicosane & $\mathrm{Bp}$ & - & - & - & + & + \\
\hline 39.12 & tetracosane & $\mathrm{Lp} / \mathrm{Dt}$ & - & - & - & + & + \\
\hline 40.7 & abietic acid, m.e. & $\mathrm{Lp} / \mathrm{Dt}$ & - & - & - & - & + \\
\hline 41.25 & 18,1-dioic acid, di m.e & $\mathrm{Bp}$ & - & - & - & - & + \\
\hline 44.17 & 20-OMe C20 fatty acid, m.e. & $\mathrm{Bp}$ & - & - & - & - & + \\
\hline
\end{tabular}

HA: humic acid; CSB: coal solubilizing bacteria; LRC: low rank coal; $\mathrm{t}_{\mathrm{R}}$ : retention time; m.e: methyl ester; Bp: plant biopolyesteres; Lg: lignin derivates; Lp/Dt: plant lipids (diterpenoids); Mic: microbial bioproducts; Pr: protein derivatives.

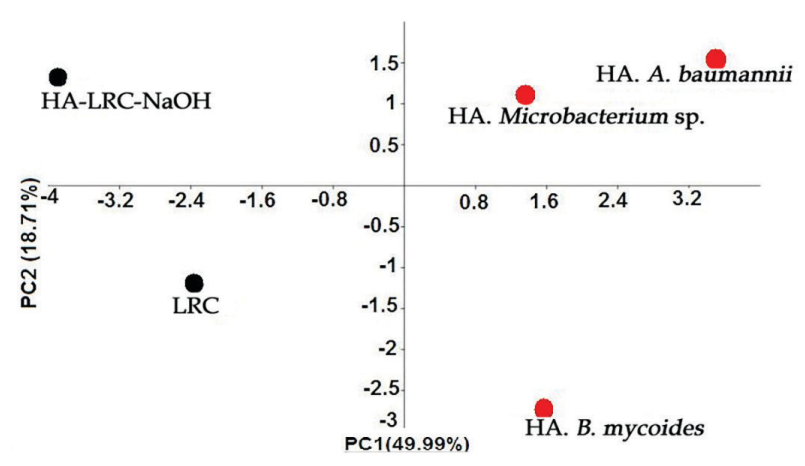

Figure 4. Association from the principal component analysis between the characteristics of the HA-BSC, HA- $\mathrm{NaOH}$ and LRC, based on the TMAH-thermochemolysis products.

ester of hexadecanoic acid and octadecanoic acid. The LRC sample shared the presence of some molecules, both with the HA-CSB and the HA-NaOH; however, they did not share most of compounds observed at the end of the chromatogram, which basically corresponded to long aliphatic chains.

In general, the type of molecules characteristics found in the two types of characterized HA was quite similar to the characteristic patterns of humic fractions of different types of compost from different plant residues; $;^{21,42}$ however, the molecules were exclusively bioproducts of microbial metabolism in only HA-CSB samples.

The results of TMAH-thermochemolysis-GC-MS analysis showed evidence of not only the efficiency of the LRC bacterial solubilization process, but also of the metabolic activity, using the products of the solubilization forming molecules that give rise to pyrolysis products that are fairly different from those obtained with alkaline extraction of HA from LRC. This indicates that CSB may have the mechanisms described in the literature to solubilize LRC; ${ }^{26}$ however, once LRC is solubilized and the HS contained in its structure is released, the CSB may continue transforming HS, perhaps combining nitrogenous products that result from its metabolism and incorporating them into the superstructure of the HA; this is noted by the presence of peptide derivatives and compounds that are considered biomarkers of molecules caused by microbial synthesis, such as methyl esters from dodecanoic, tetradecanoic, pentadecanoic and hexadecanoic acids. ${ }^{21}$ 
It is also possible that the synthesis of long chain fatty acids by CSB, when supplied with the same LRC that was initially solubilized, results in the incorporation of these compounds into the HA supramolecules. This idea is supported by previous studies in which the ability of certain microorganisms to partially degrade HA has been described, generating greater quantities of HA with lower molecular weight ${ }^{43,44}$ and carrying out repolymerization, forming one suprastructure with different characteristics from the initial one. ${ }^{1}$ This fact is related to the role attributed to bacteria in the formation of HS through the diagenesis stage in the process of coalification and resynthesis, polymerization and condensation of humic precursors in the natural process of humification in soil. ${ }^{45}$

\section{Size exclusion chromatography}

Table 4 shows the average number of different molecular weights $(\mathrm{Mn})$, the average molecular weight $(\mathrm{Mw})$ and the polydispersity (P) for each HA samples. Higher values of Mw were found for the three HA-CSB, as compared with the HA- $\mathrm{NaOH}$. It was found that the distribution of molecules with different molecular weight (Mn) was greater for the HA-CSB, which means there was greater heterogeneity for the different structures of the HA. All HA have high P values; however, the value does not vary strongly as compared with the above parameters, except for the HA-CSB A. bumannii, which shows a higher polydispersity than other HA.

The results obtained with the high-performance size exclusion chromatography (HPSEC) analysis were also consistent with the assumption made above for the activity of the CSB for the repolymerization and modification of the HA suprastructure originally solubilized from the LRC, in addition to the new organic molecules synthesized by the CSB, contributing to the increase in $\mathrm{Mw}, \mathrm{Mn}$ and $\mathrm{P}$, generating larger and more diverse HA supramolecules from the different molecules that made up the suprastructure.

Finally, the concept of supramolecular structures of the HS postulates that they are not macromolecules, but behave as supramolecular associations of weakly joined single humic molecules; ${ }^{1}$ therefore, they are in constant change and reorganization, which defines the interactions that cause effects on plants, microorganisms and soil physical properties; ${ }^{2}$ accordingly, HA-CSB, since it is less condensed, perhaps could present more dynamic opportunities to interact with other organic and mineral fractions from soil, as well as from the roots of plants and the microbiota.

\section{Conclusions}

Within the products that were generated with the transformation of the LRC through CSB activity, there was a fraction that exhibited molecular characteristics that are typical of humic matter, i.e, HA; however, the HA-CSB had certain structural differences when compared with the $\mathrm{HA}-\mathrm{NaOH}$.

The HA present in the LRC were structurally transformed by the CSB, generating supramolecules that retained the humification degree, but had a decreased oxygen content. They were enriched with nitrogenated compounds and showed less aromatic condensation, which gave them a more hydrophilic characteristic that is associated with the predominance of polar aliphatic molecules.

The degradation activity, resynthesis of humic precursors, and repolymerization of the HA in the LRC were revealed by the CSB activity, as evidenced by the presence of fatty acids that can only be synthesized by microbial activity, higher molecular weights and polydispersity in the HA-CSB.

\section{Acknowledgments}

The authors would like to thank Carbones del Cerrejon Limited and COLCIENCIAS (Colombia) for sponsoring this research and acknowledge the Universidad Popular del Cesar and Universidad Nacional de Colombia.

The authors give special thanks to Dr Alessandro Piccolo, Dr Ricardo Spaccini, research group of Supramolecular

Table 4. Parameters related to the molecular weight of the HA-CSB and HA-NaOH fractions, determined with size exclusion chromatography $(\mathrm{n}=3)$

\begin{tabular}{lccc}
\hline HA sample & $\mathrm{Mw} \pm \mathrm{SD} / \mathrm{Da}$ & $\mathrm{Mn} \pm \mathrm{SD}$ & $\mathrm{P} \pm \mathrm{SD}$ \\
\hline HA-NaOH & $3745 \pm 147^{\mathrm{a}}$ & $526 \pm 2^{\mathrm{a}}$ & $7.11 \pm 0.29^{\mathrm{a}}$ \\
HA-CSB A. baumannii & $6617 \pm 234^{\mathrm{c}}$ & $692 \pm 12^{\mathrm{c}}$ & $9.57 \pm 0.42^{\mathrm{b}}$ \\
HA-CSB B. mycoides & $4525 \pm 376^{\mathrm{b}}$ & $667 \pm 22^{\mathrm{c}}$ & $6.78 \pm 0.34^{\mathrm{a}}$ \\
HA-CSB Microbacterium sp. & $4404 \pm 66^{\mathrm{b}}$ & $602 \pm 14^{\mathrm{b}}$ & $7.32 \pm 0.29^{\mathrm{a}}$ \\
\hline
\end{tabular}

HA: humic acid; CSB: coal solubilizing bacteria; Mw: average molecular weight; Mn: average number of different molecular weights; P: polydispersity; SD: standard deviation. Treatments with different letters show significant difference (low significant difference (LSD), $\alpha=0.05$ ). 
Humic Systems in the Environment and Universita di Napoli Federico II.

\section{References}

1. Piccolo, A.; Cozzolino, A.; Conte, P.; Spaccini, R.; Naturwissenschaften 2000, 87, 391.

2. Theng, B. In Developments in Clay Science, vol. 4; Elsevier: Amsterdam, The Netherlands, 2012, ch. 12.

3. Piccolo, A.; Mbagwu, J. S.; Soil Sci. Soc. Am. J. 1999, 63, 1801.

4. Piccolo, A.; Spaccini, R.; Nieder, R.; Clim. Change 2004, 67, 329.

5. Bandeira, M.; Mosca, G.; Vamerali, T.; Desalination 2009, 246, 78.

6. Trevisan, S.; Francioso, O.; Quaggiottil, S.; Nardi, S.; Plant Signaling Behav. 2010, 5, 635.

7. Calvo, P.; Nelson, L.; Kloepper, J. W.; Plant Soil 2014, 383, 3.

8. Dobbss, L. B.; Canellas, L. P.; Olivares, F. L.; Aguiar, N. O.; Peres, L. E. P.; Azevedo, M.; Spaccini, R.; Piccolo, A.; Façanha, A. R.; J. Agric. Food Chem. 2010, 58, 3681.

9. Zandonadi, D. B.; Santos, M. P.; Dobbss, L. B.; Olivares, F. L.; Canellas, L. P.; Binzel, M. L.; Façanha, A. R.; Planta 2010, 231, 1025.

10. Zandonadi, D. B.; Santos, M. P.; Busato, J. G.; Peres, L. E. P.; Façanha, A. R.; Theor. Exp. Plant Physiol. 2013, 25, 13.

11. Canellas, L. P.; Dantas, L.; Aguiar, N.; Perez, L.; Zsogon, A.; Olivares, F.; Dobbss, L.; Façanha, A.; Nebbioso, A.; Piccolo, A.; Ann. Appl. Biol. 2011, 159, 202.

12. Canellas, L. P.; Olivares, F. L.; Chem. Biol. Technol. Agric. 2014, 1,1 .

13. du Jardin, P.; Sci. Hortic. 2015, 196, 3.

14. Nardi, S.; Pizzeghello, D.; Schiavon, M.; Ertani, A.; Sci. Agric. 2016, 73, 18.

15. Puglisi, E.; Fragoulis, G.; Ricciuti, P.; Cappa, F.; Spaccini, R.; Piccolo, A.; Trevisan, M.; Crecchio, C.; Chemosphere 2009, $77,80$.

16. Lima, L. S.; Olivares, F. L.; de Oliveira, R. R.; Vega, M. R. G.; Aguiar, N. O.; Canellas, L. P.; Chem. Biol. Technol. Agric. 2014, 1,1 .

17. Valenzuela, E. I.; Prieto-Davó, A.; López-Lozano, N. E.; Hernández-Eligio, A.; Vega-Alvarado, L.; Juárez, K.; Cervantes, F. J.; Appl. Environ. Microbiol. 2017, 83, e00645-17.

18. Martinez, C. M.; Alvarez, L. H.; Celis, L. B.; Cervantes, F. J.; Appl. Microbiol. Biotechnol. 2017, 97, 10293.

19. Senesi, N.; Plaza, C.; Brunetti, G.; Polo, A.; Soil Biol. Biochem. 2007, 39, 1244.

20. Nebbioso, A.; Piccolo, A.; Biomacromolecules 2011, 12, 1187.
21. Spaccini, R.; Piccolo, A.; Soil Biol. Biochem. 2009, 41, 1164.

22. Giannouli, A.; Stavros, K.; Siavalas, G.; Chatziapostolou, A.; Christanis, K.; Papazisimou, S.; Papanicolaou, C.; Foscolos, A.; Int. J. Coal Geol. 2009, 477, 383.

23. Fakoussa, R.; Hofrichter, M.; Appl. Microbiol. Biotechnol. 1999, $52,25$.

24. Valero, N. O.; Rodriguez, L. N.; Mancilla, S.; Contreras, L.; Acta Biol. Colomb. 2012, 17, 337.

25. Valero, N.; Gómez, L.; Pantoja, M.; Ramírez, R.; Braz. J. Microbiol. 2014, 45, 911.

26. Hofrichter, M.; Fakoussa, R. In Biopolymers, vol. 1; Hofrichter, M.; Steinbüchel, A., eds.; Wiley-VCH: Weinheim, Germany, 2004, ch. 14.

27. Muscolo, A.; Sidari, M.; Nardi, S.; J. Geochem. Explor. 2013, 129, 57.

28. Canellas, L. P.; Dobbss, L. B.; Oliveira, A. L.; Chagas, J. G.; Aguiar, N. O.; Rumjanek, V. M.; Piccolo, A.; Eur. J. Soil Sci. 2012, 63, 315.

29. ASTM D388-18: Standard Classification of Coals by Rank; ASTM International: West Conshohocken, PA, 2018.

30. Yuan, H.; Yang, J.; Chen, W.; Fuel 2006, 85, 1378.

31. http://humic-substances.org/isolation-of-ihss-soil-fulvic-andhumic-acids/, accessed in June 2017.

32. Piccolo, A.; Adv. Agron. 2002, 75, 57.

33. Lu, X. Q.; Hanna, J. V.; Johnson, W. D.; Appl. Geochem. 2000, 15, 1019 .

34. Adani, F.; Spagnol, M.; J. Environ. Qual. 2008, 37, 1608.

35. Dong, L.; Yuan, Q.; Geomicrobiol. J. 2009, 26, 484.

36. Dong, L.; Yuan, Q.; Yuan, H.; Fuel 2006, 85, 2402.

37. Selvi, A.; Banerjee, R.; Ram, L.; Singh, G.; World J. Microbiol. Biotechnol. 2009, 25, 1713.

38. Kleber, M.; Environ. Chem. 2010, 7, 320.

39. Nardi, S.; Pizzeghello, D.; Muscolo, A.; Vianello, A.; Soil Biol. Biochem. 2002, 34, 1527.

40. Canellas, L. P.; Zasdonadi, D.; Busato, J.; Baldotto, M.; Simões, M.; Martin-Neto, L.; Façanha, A. R.; Spaccini, R.; Piccolo, A.; Soil Sci. 2008, 173, 624.

41. Kucerik, J.; Smejkalova, D.; Cechlovska, H.; Pekar, M.; Org. Geochem. 2007, 38, 2098.

42. Deport, C.; Lemee, L.; Ambles, A.; Org. Geochem. 2006, 37 , 649.

43. Hofrichter, M.; Bublitz, M.; Fritsche, M.; Fuel Process. Technol. 1997, 52, 55.

44. Kidralieva, K.; Geophys. Res. Abstr. 2006, 8, 3.

45. Van-Trump, J. I.; Sun, Y.; Coates, J. D.; Adv. Appl. Microbiol. 2006, 60, 55. 